\title{
Application of Site Management in Enterprise Lean Production
}

\author{
Duolin He \\ School of Economics and Management \\ Beijing Jiaotong University \\ Beijing, China
}

\author{
Liping Shao \\ School of Economics and Management \\ Beijing Jiaotong University \\ Beijing, China
}

\begin{abstract}
Improvement of site management is one of the effective ways to reduce costs and improve efficiency, with little investment and quick results. Field management includes 5S, customization management and visual management. This paper uses the above theory to improve and optimize the production site of the workshop. The original workshop is dirty, disorderly and poor, the goods and tools are placed randomly, and the appearance of staff is not good. The workshop equipment is arranged in an orderly manner; the tools and articles are managed in a fixed way; the ground is clean and pollution-free; workers work according to the rules and regulations, and the company's image and quality are improved.
\end{abstract} cycle

Keywords-5S; customization management; visual; PDCA

\section{INTRODUCTION}

With the continuous progress of science and technology in today's world, more and more high-tech is applied to manufacturing enterprises, such as robots, robotic arms and so on. Instead, people ignore the production site which is most directly related to products. Therefore, enterprises want to improve their own benefits, not only need to reduce costs, introduce high-tech, improve productivity, but also pay attention to on-site management and improvement. $5 \mathrm{~S}$ is a sharp tool of on-site management. When applied to enterprises, the cost is low, but the effect is quick, and the benefits are considerable. For small and medium-sized enterprises, it is a very good choice, especially in line with China's current serious overcapacity, enterprise-intensive situation.

\section{PRESENT SitUATION ANALYSIS OF WORKSHOP PRODUCTION SITE}

In recent years, the market demand for high-speed rail has increased, which leads to the increase of the demand for train motors, the increase of the company's tasks and the increase of workshop production. Therefore, the enterprise neglects the onsite management in order to complete the production plan.

According to the on-site investigation in the workshop, the following main problems exist:

- Raw materials, finished products, semi-finished products, components, repairs, defective products, etc. are not clearly placed in a clear area and are placed everywhere, resulting in chaotic workplaces, difficulties in finding work pieces, increasing the labor intensity and time of workers, seriously affecting the company's image, and not conducive to internal management.

- The inappropriate placement of machinery and equipment often results in the accumulation and occupancy of passages, resulting in unobstructed work flow and increasing the difficulty and time of work piece handling.

- All kinds of production tools needed in the production process, some of which have not been put back after use, such as casually discarded by employees after use; some of which have not been set up and are searched everywhere when used, seriously delaying the production process.

- Fire-fighting corridors and working areas need to be set.

- On-site management awareness of personnel has not been strictly implemented and insufficient attention has not been paid to the standards designated by the company.

\section{IMPLEMENTATION STEPS OF SITE MANAGEMENT}

\section{A. PDCA Cycle}

1) Plan (D): This step is to observe the current situation and find out the problems. When carrying out management activities, it's needed to analyze the current situation of workshop, identify the problems to be solved, further determine the key points for improvement, and formulate detailed plans.

When making a plan, $5 \mathrm{~W} 1 \mathrm{H}$ 's question method is used:

- Why to do?

- What effect can be achieved?

- Where to execute?

- Who will do it?

- When will it be finished?

- How to finish it? 
2) Implementation $(D)$ : This step includes the following steps:

- To train personnel, the main content is the process and essentials of implementing activities.

- To further subdivide the management activities and assign corresponding tasks.

- Guiding employees to participate, putting forward suggestions for improvement, and further improving the plan.

- The final confirmation of the plan of management activities can be carried out with the consent of the majority of personnel.

3) Inspection $(C)$ : In this step, the following steps are needed to do:

- Checking the progress of implementation to ensure the completion of tasks in accordance with the stipulated time

- Checking the effect of implementation to ensure that the expected purpose can be achieved.

- Collecting and analyzing the problems in the process of implementation, and take pertinent measures to correct them.
4) Feedback (A): What needed to do in this step are:

- Comparing the situation before and after the implementation of the activities, sorting out typical cases and effective methods.

- Summarizing experience and formulating relevant rules and regulations.

- The next PDCA cycle solves the unresolved problems.

\section{B. Specific Implementation Measures of $5 S$}

1) Seiri: In the process of improvement, the labeling method is used to mark the places urgently needed to be sorted out in the workshop with red labels, so that the areas needing improvement can be directly seen by the staff, and the improvement should be earnestly carried out. In the labeling method, first of all, the items that need to be sorted out should be distinguished, such as raw materials, finished products, semi-finished products, components, fixtures, machinery and equipment, assembly line and so on. Then set the red label benchmark, issue the notice as required, record and track the progress of improvement in the process of improvement. (See "Table I")

TABLE I. IMPROVEMENT PROJECTS FOR EFFICIENCY IMPROVEMENT IN MACHINE ONE WORKSHOP

\begin{tabular}{|c|}
\hline Improvement personnel: \\
Project Category: Efficiency Category \\
Description current status: \\
Improvement end time: \\
There are 35 production teams, one team leader and two deputy team leaders in the first machine workshop. The \\
operation time of some processes is unbalanced, and bottleneck processes are prone to occur, resulting in the \\
production line can not be carried out in an orderly manner, which seriously wastes human resources.
\end{tabular}

2) Seiton: "Rectification" is to place items according to operating standards, so that staff can immediately find the required items, reduce unnecessary labor time, and manage the items according to the principle of "fixed-point, positioning, quantitative", so as to improve work efficiency, improve product quality, reduce management costs and achieve maximum benefits. Its purpose is to control inventory and prevent backlog of funds. (See "Table II")
Improvement measures for items are as follows:

- Items should be placed in a fixed position to facilitate searching and reduce errors caused by confusion.

- Categorizing and sorting out the items and mark them according to the prescribed labels, so as to be striking and neat. 
TABLE II. Storage Method of ToOl Usage Frequency IN Machine-1 Workshop

\begin{tabular}{|c|c|c|}
\hline Demand degree & Table column head & Processing method \\
\hline low & Less than twice a year & Remove tool library \\
\hline & No more than five times a year & Put it in the inner position \\
\hline & Once a month & Put it in the middle \\
\hline nedium & Once a month & Put it in the middle \\
\hline high & Once a week & Put it a little closer to the outside. \\
\hline & Once a class & $\begin{array}{c}\text { Easily accessible on the outermost } \\
\text { layer }\end{array}$ \\
\hline
\end{tabular}

\section{3) Seiso} cleaning.

a) Establishing specific time and requirements for

Daily cleaning: 10 minutes a day

Contents include - workplaces, logistics channels, balconies, offices, toolboxes, other equipment, etc.

Weekly cleaning: 30 minutes a week
Contents include cable, ceiling, lampshade, large file cabinet, pipeline, etc

\section{b) Strengthening routine maintenance:}

In this step, it is necessary to strengthen supervision and inspection on the implementation of daily inspection, weekly cleaning and minor maintenance of equipment, and publicize the inspection results weekly as a basis for evaluation and punishment. (See "Table III")

TABLE III. CONTRAST Diagram OF EQUiPMENT MaINTENANCE

\begin{tabular}{|c|c|}
\hline Project & Solution \\
\hline Daily maintenance & Daily and weekly maintenance \\
\hline Regular maintenance & Fixed maintenance minor repairs \\
\hline Air Operation Maintenance & Long shutdown \\
\hline Preventive maintenance & Targeted Maintenance \\
\hline Deep Maintenance & Full maintenance during deep gap period \\
\hline
\end{tabular}

4) Seiketsu: Cleaning is to carry out the activities of the first $3 \mathrm{~S}$ to the end and to institutionalize and standardize them. Enterprises should formulate strict rules and regulations to implement activities to every corner of the workshop.

The design scheme is as follows:

- Implementation of the first three $\mathrm{S}$ (collation, consolidation and cleaning.

- Regular training of employees to make "tidiness" a habit.

- Strengthening the sense of responsibility and set up responsible persons.

- Establishing a good system of equipment spot inspection.

- The 5S Management Committee and the head of each team should deal with the problems in time and check the rectification results.

5) Shitsuke: Literacy is an important guarantee for the healthy development of an enterprise. If employees in an enterprise can work conscientiously, actively, abide by rules and regulations, and form good habits, then the process of managing staff will be very easy.

The design scheme is as follows:

- Continuing to implement the activities of the first $4 \mathrm{~S}$

- Establishing rules and regulations that are generally accepted

- Regular education and training

- Strengthening the reward and punishment mechanism

- Constantly organizing positive activities

\section{Implementation Scheme of Visual Management}

Visual management can create a clear production site. Field managers can know whether the production site is in a normal state through visual function. If problems are found, they can take immediate corrective and improvement actions. (See "Table IV") 
TABLE IV. IMPLEMENTATION Plan OF Visual MANAGEMENT PlaN

\begin{tabular}{|c|c|c|c|}
\hline Category & Improve content & Improvement plan & Remarks \\
\hline Personnel management & Employee image & $\begin{array}{l}\text { Employees must wear overalls and } \\
\text { safety hats when entering the } \\
\text { workshop. Snacks and drinks are } \\
\text { forbidden to enter the workshop }\end{array}$ & \\
\hline \multirow{3}{*}{ Goods management } & Lounge Goods Managemen & $\begin{array}{l}\text { Lounge items are placed in a fixed } \\
\text { area and marked }\end{array}$ & \\
\hline & $\begin{array}{l}\text { Goods Management in } \\
\text { Workshop Office Area }\end{array}$ & $\begin{array}{l}\text { The articles and documents in the } \\
\text { workshop office area should be laid } \\
\text { down according to the standard }\end{array}$ & \\
\hline & Personal clothing placement & $\begin{array}{l}\text { Additional hanger for } \\
\text { employees'clothes }\end{array}$ & \\
\hline \multirow[b]{2}{*}{ Equipment, Tool Management } & Equipment labeling & $\begin{array}{l}\text { Complete label of equipment fixed } \\
\text { assets to ensure accurate information }\end{array}$ & \\
\hline & Tool store & $\begin{array}{c}\text { Processing tools should be neatly } \\
\text { placed, easily accessible and visually } \\
\text { effective }\end{array}$ & \\
\hline
\end{tabular}

\section{Set-up Management Implementation}

1) Clearing up things unrelated to production: Everything that has nothing to do with production in the production site should be cleaned up.

2) Setting according to the fixed plan: All workshops and departments should classify, move, transfer, adjust and locate the production site and appliances according to the requirements of the fixed drawing.

3) Placing standard information brand names: Placement of standard information brand names should be in line with the brand, object and picture, and be managed by a special person, and should not be moved.

The investigation of fixed-position management can be divided into two situations. First, after acceptance and implementation of the results, the acceptance results are unqualified and resolutely not let go, re-implementation of management measures until qualified; second, irregular spot management for surprise inspection and assessment.

The basic index of setting assessment is the setting rate, which indicates the degree to which the items that must be set in the production site have been set.

SET RATE $=\sqrt{\frac{\text { Number of items actually set }}{\text { Number of items specified }}} * 100 \%$

Setting rate index grade: excellent - 95\%, good - 90\%, qualified $-85 \%$. Among them, excellent rewards should be continued, qualified measures should be improved to achieve better results. Failure to pass directly requires re-planning of fixed measures until they are qualified.

Inspector 1 workshop assembly line has five fixed areas, including material storage area, 20 items in the area to be tested, 3 items not fixed; 25 parts in the semi-finished area, 4 items not fixed; 5 items in the bad product area, all of which are fixed, the fixed rate of the place is determined.

$$
\text { SET RATE }=\sqrt{\frac{(20+25+5)-(3+4+0)}{20+25+5}} * 100 \%=86 \%
$$

The result of this inspection is $86 \%$, so the next step is to improve the aspects that are not well set, and improve the setting rate of the next inspection.

\section{CONCLUSION}

Through the investigation of the workshop production site, effective implementation methods and evaluation schemes are formulated for the problems found. Improving the unreasonable areas in the workshop, the production equipment has formulated a sound management system of use, maintenance and overhaul, and strictly implemented; the various signs in the production area are obvious, the functional areas are clearly divided, and regular inspection is strictly carried out. It improves the production efficiency of the workshop, saves space and time costs, improves the production environment, and cultivates the staff's awareness of saving and efficient work.

\section{REFERENCES}

[1] Li Haining. Specific Methods and Measures of Workshop Production Management [J]. New Business Weekly, 2019, (7): 33-35.

[2] Huangying. Application of Lean Production Management in Enterprise Management [J]. Shandong Industrial Technology, 2019, (14): 232.

[3] Yang Guang. On-site Operation Risk and Management Measures in Machine Shop [J]. Value Engineering, 2018 (34): 44-45.

[4] He Lintao. Overview of Workshop Field Management Based on Lean Production [J]. Architectural Engineering and Design, 2018, (22): 40, 76

[5] $\mathrm{Hu}$ Wanhua. Application of Standardized Work in Enterprise Lean Production [J]. Value Engineering, 2018, 37 (20): 52-53.

[6] Zeng Pengfei, Ren Kaibin, Zhang Xing. Integrated Workshop Production Management System for Lean Production [J]. Mechanical Engineering, 2018, 37 (1): 51-57.

[7] Wang Li, Jiang Guozhang, Xiangfeng, Research on Evaluation Method of Lean Production Level in Manufacturing Enterprises [J]. Scientific Management Research, 2018, 38 (12): 114-118. 
[8] Bao Honggang. Holographic Scanning of Manufacturing Field Management [J]. Enterprise Management, 2018, (11): 86-89.

[9] Yu Zhenshan. Visual Management Strategies and Tools [J]. Modern Occupational Safety, 2018, (6): 35-37.

[10] Zuo Chunlin. Application of Lean Production in Assembly Workshop of V Company [D]. Donghua University, 2017 (05). 